\title{
Exploring digital marketing resources, capabilities and market performance of small to medium agro-processors. A conceptual model.
}

\author{
More Chinakidzwa \\ Maxwell Phiri \\ University of KwaZulu-Natal (UKZN), South Africa
}

\section{Keywords}

Agro-processors, digital marketing, resources, capabilities, market performance.

\begin{abstract}
Agro-processors are important to economies of developing countries as they help create jobs, alleviate poverty and improve food security. These goals are important for Zimbabwe - a country ranked among the poorest countries in the world. However, small to medium sized agro-processors face marketing challenges, especially in the digital environment. The challenges are mainly due to limited digital marketing resources and capabilities as witnessed by poor website design, and low visibility in trending social media platforms. As such, marketing costs remain high, yet digital marketing provides an opportunity to cut costs, increase visibility, improve customer relationships, offer enhanced market sensing, and increase customer convenience. In view of these possible contributions, this paper sought to establish whether possession of certain digital marketing resources and capabilities can improve agro-processors' market performance. This is important because marketing is contextual, theories and concepts that apply in developed markets are not easily applicable to developing countries. As such, a new set of skills and knowledge is required. This paper contributes to literature on resource-based view, marketing capability, subsistence marketing, and marketing performance. To achieve that, the researchers reviewed and developed a conceptual model using literature on digital marketing, marketing resources, capabilities and market performance.

The model and paper at large are original in that it takes a digital marketing and developing country perspective. Extant literature in Zimbabwe lacks an explanation to the impact of digital marketing resources, and capabilities on market performance of agro-processors. The study implies that different markets and contexts require different knowledge and skills; as such, researchers must test existing and new frameworks in different environments to develop relevant knowledge.
\end{abstract}

Corresponding author: More Chinakidzwa

Email addresses for the corresponding author: more.chinaz@gmail.com

First submission received: 23' July 2019

Revised submission received: $9^{\text {th }}$ September 2019

Accepted: $5^{\text {th }}$ November 2019

\section{Introduction}

We cannot ignore the strategic importance of digital marketing resources and capabilities in this challenging digital environment. This is so because, digital marketing, which is the application of digital technologies to achieve marketing objectives (Chaffey \& Smith, 2017) requires new set of skills and knowledge (Wymbs, 2011) since marketers cannot easily apply traditional marketing approaches to the digital environment. Agro-processors can thus immensely benefit from this new set of skills and knowledge. An agro-processor is a firm that 'processes raw materials and intermediate products derived from agriculture, forestry and fisheries' (Food and Agriculture Organisation (FAO), 1999). The agroprocessing value chain includes processes after harvesting until product reaches final consumer (Mhazo, Mvumi, Nyakudya \& Nazare, 2012) as such different levels and classifications of agro-processors exist. Mhazo, et al., (2012) classified agro-processors into primary and secondary processors. Primary processing mainly occurs at the farm and involves making produce ready for storage, marketing or further processing. Secondary agro-processing involves more value addition to original products, with entire change to the product giving high market value (Mhazo, et al., 2012). This classification contradicts Thindisa (nd) cited by Rambe, (2018) who differentiated agro-processing from value addition. According to Thindisa (nd) agro-processing involves change in state or form whilst value addition is anything that 
gives more value to a product. Accordingly, we cannot classify harvesting and packaging of fruits and vegetables into agro-processing but value addition. However, FAO, (1999) classify "fresh" fruits and vegetables as processed goods undergoing sophisticated operations in collection, quality control, packaging, storage, refrigeration and transport". FAO (1999) further provides another classification of upstream and downstream processors. Upstream processors engage in initial processing such as flour milling whilst downstream processors further manufacture products from the initial stage. The FAO (1999) perspective neglect some of the initial processing that occur immediately after harvesting such as shelling which Mhazo, et al., (2012) clearly spelt out.

As such, this study considers upstream processors to be involved in initial processing such as milling, oil pressing but excludes farm activities such as drying and shelling. We consider fresh fruits and vegetables that go through special handling, packaging and processing into upstream agro-processing. Downstream processing is limited to further processing of products from upstream activities such as bread, biscuit, and furniture making. The authors take the perspective that agro-processing is part of value addition regardless of whether the product changes form or not, even if a processor cleans and packs a product, agro-processing would have taken place.

However, there is need to adopt an approach that clearly show broad categories of processes included in agro-processing. As such, this study adopts the UN International Standard Industrial Classification of All Economic Activities (ISIC) classifications in addition to the upstream and downstream categorization. The ISIC classification comprises i. Manufacture of food, beverages and tobacco; ii. Textile, wearing apparel and leather; iii. Manufacture of wood and wood products, including furniture; iv. Manufacture of paper and paper products, printing and publishing; v. Manufacture of rubber products. This means all small to medium enterprises (SME) fitting into the ISIC classification are included in this study with an SME being a firm with between 5-75 employees according to the Zimbabwe Revenue Authority classification.

\section{Significance of Agro-processors}

Development of agro-processors is critical for Zimbabwe - a country ranked one of the five poorest countries in the world on GDP per-capita in purchasing power parity (Rivera-Santos, et al., 2015). Poverty is far worse in rural than urban areas (UN Zimbabwe, 2016) yet rapid growth of SME agro-processors reduce poverty, contribute towards job creation and uplift living standards especially women (AmpaduAmeyaw \& Omari, 2015). The link between processors and farmers provides an avenue for income to farmers who are generally rural settlers. In Zimbabwe, food and beverages dominate employment (Mhazo, et al., 2012) whilst furniture making has grown to become one of the most expanded and established sectors. A Finscope (2013) study show that $46 \%$ of the adult population is micro, small to medium enterprise (MSME) owners with $43 \%$ working in agriculture. Reliance on agro-processing and SMEs is not unique to Zimbabwe but the whole Sub-Saharan Africa (Mhazo, et al., 2012) as SMEs constitute the largest share of private-sector enterprises and contribute the bulk of employment (Reeg 2015; Ampadu-Ameyaw \& Omari, 2015). Therefore, agro-processors are key to industry and economic growth (Reeg, 2015; Mhazo, et al., 2012; FAO, 1999).

\section{Agro-processing Drivers in Zimbabwe}

The land reform led to the emergence of indigenous farmers who established themselves as new key suppliers to emerging agro-based manufacturers. As a result, SME agro-processors flourished in large cities such as Harare. Statutory instrument 64 (S.I 64) of 2016 controlled importation of selected products thus driving local manufacturing high. Import controls led to a fall in imports resulting in local supplies covering the gap. This led to a rise in capacity utilization of local firms. In the process, the role of SMEs became dominant as they found huge opportunities in gaps left by large firms (Mapakame, 2017). Large firms continue to downsize, retrench and close due to harsh economic conditions leading to some large processors relegating sourcing and production to SMEs (Mhazo, et al., 2012). Furthermore, growth in information communication technologies continues to influence business environment as there is a remarkable growth in digital business services driven by a rise in Internet access. Internet usage rose to 6.9million active users as of December 2017, an increase of 3.7\% to the 2016 figure. According to POTRAZ, (2017) active mobile subscriptions continue to grow with a $9.4 \%$ increase to reach 14,09 million in a country 
with a population of 16 million, $102.7 \%$ mobile penetration providing huge mobile marketing opportunities. For four consecutive years, voice traffic had been declining whilst mobile data usage increase creating more opportunities for digital businesses. Overall, the prevailing economic environment favours SMEs because these firms can easily access raw materials from small-scale producers, easily link with emerging farmers, and ready access to informal networks, cheap raw materials, and niche marketing capabilities (Mhazo, et al., 2012). This nexus between small-scale farmers and SME agro-processors generally promote development through informal linkages, cultural connections and long term established relational networks. However, we do not know the value and contribution of these resources to digital marketing activities of agro-processors. Knowledge of the influence of informal linkages, cultural connections and relationships to digital marketing activities and performance is important because extant research show that digital marketing has potential to alleviate some marketing challenges faced by SMEs. As it is, agro-processors' contribution remains small (Reeg, 2015) yet the prevailing economic environment favours them. This call for research to understand what resource and capability needs influence these agro-processors market performance and overall contribution to economic performance.

\section{Major Challenges to Agro-processors}

SMEs lack market visibility (Gilmore, Gallagher \& Henry, 2007) as a result suffer poor market performance, as sales remain subdued with low profit margins \& brand awareness. In Zimbabwe, lack of marketing skills and market information appears to be a major problem (Mhazo, et al., 2012). Most SMEs fail to perform because they lack intelligence and information on market trends and opportunities (Zindiye, Chiliya \& Masocha, 2012). Agro-processors also encounter challenges in processing technology, standards, quality and regulatory enforcement (Mhazo, et al., 2012) market access, market-linkages and demand management. For instance, great opportunities exist in fresh fruits and vegetables, but majority of producers find it difficult to access these markets (Mhazo, et al., 2012).

Research has found digital marketing to be important because it provides opportunities to increase sales, add value, get closer to customers, offer online brand extension, have wide reach - all at low cost (Chaffey \& Smith 2017) thus helping overcome restrictions often faced by SMEs. However, no research exists to test the impact of digital marketing resources and capabilities on SMEs agro-processors' market performance in Harare, Zimbabwe. Yet, the digital era has unsettled traditional marketing changing all facets of marketing by creating dynamic and complex markets that require new marketing skills (Stone \& Woodcock, 2014). However, the complexity and level of new skills required in the Zimbabwean context is not known. Nevertheless, marketers' mind-set has to change to fit the new environment (Stone \& Woodcock, 2014) and build new models that allow customer attraction, engagement, retention, learning, and relationships (Parsons, Zeisser \& Waitman, 1998). The unique features and capabilities of digital marketing to transform marketing call for changes in organisational structures (Parsons, et al., 1998) and require new set of resources and capabilities (Wymbs 2011; Morgan, Slotegraaf \& Vorhies, 2009). No research shows digital marketing resources and capabilities of agro-processors in Harare, as a result there is need to establish the extent to which marketers must develop and deploy new resources. In addition, we do not know how digital marketing resources and capabilities can influence market performance of agro-processors.

In view of the significance, challenges and roles of digital marketing, this study sought to develop a conceptual model that interrogates if possession of certain digital marketing resources, and capabilities can improve market performance of SME agro-processors in Harare, Zimbabwe. To achieve this, we structured the paper as follows, methodology, theoretical and conceptual development, conclusions, implications, limitations, and further research.

\section{Methodology}

This is a conceptual paper. The researchers conducted literature searches on online databases primarily Google Scholar, Science Direct and EBSCO Host. Key words such as digital marketing, agroprocessors in Zimbabwe, small to medium enterprises, the resource-based view in marketing, capabilities approach, and e-marketing guided searches in these online databases. The researchers sorted search results by relevance to the search term and considered only the first three pages of the search results. The 
page limit was necessary because some searchers returned thousands of results, but the first pages were most relevance because of the relevance filter. For example, a search for the term 'digital marketing' on Science Direct returned 36502 results, whilst 'e-marketing' gave a result of 156028 . However, more specific terms such as 'SMEs digital marketing', 'Zimbabwe SMEs', and 'agro-processors' returned less results although impossible to open all of them. As a result, the researchers managed to apply their judgement of the obtained papers basing on relevance to the subject that was mainly digital marketing resources, capabilities and market performance. In addition, recent papers of less than five years were more preferable although not a key determinant because some theoretical concepts date back to the 80s. To develop a strong conceptual background, the researchers also checked citations and references by other researchers in the subject. This approach led to more articles that were relevant and gave access to leading authors in the subject. The researchers relied only on peer-reviewed journals that publish either conceptual, empirical or review papers.

\section{Theoretical and Conceptual Development The resource-based view (RBV)}

The resource-based view attributes performance differences in firms to differences in resources. Resources are 'a bundle of assets, capabilities, and organizational processes, firm attributes, information, and knowledge' (Barney, 1991; Barney \& Hesterly, 2015). According to the RBV, resources that are rare, valuable, and inimitable create competitive advantage for the firm. Firms can be in a strong position in the marketplace by leveraging marketing resources and these can be brand reputation, customer relationships, and market orientation (Srivastava, Shervani, \& Fahey, 1998). Unlike Porter's industry structure perspective, the RBV takes an internal perspective by considering a firm as a bundle of resources. Although both perspectives help explain performance differences in firms, Porter's industry structure perspective expressed by the five forces model consider industry structure as an important determinant of firm performance. According to Porter $(1979,2008)$ firms must manage or control forces within an industry to be able to gain competitive advantage. The five forces are the underlying factors that shape every industry structure and profitability therefore knowledge of the five forces contribute to a company's ability to position itself within an industry. The model implies that choosing an industry is a strategic choice and Porter (1980) synthesised this argument by proposing three strategies (differentiation, cost leadership and focus) to perform in an industry. It is after these considerations that firms can consider internal factors such as value chains (Hunt \& Madhavaram, 2019). However, industry-based strategies "cannot provide solid theoretical foundation for strategy in the hypercompetitive, dynamic, global economy" (Hunt \& Madhavaram, 2019). The industry structure perspective neglects the important role played by resources in tapping or managing the industry forces. Although Porter (2008) review of the five forces model, acknowledged the role of resources, Porter did not give resources the attention they deserve. Development of internal resources enable a firm to tap into external opportunities for it to succeed (Hitt, et al., 2017). Industry structure assumes that if firms do not own resources, they can be buying, which is at odds with the RBV (Teece, et al., 1997).

Therefore, this study takes the perspective that resources and industry forces are complementary (Porter, 2008; Dobbs, 2014; Teece, et al., 1997) as such attainment of competitive advantage require an understanding of all perspectives. Firms require resources to be able to take up opportunities presented by the external industry factors or to manage these factors to the firm's advantage. Porter 's five forces model fails to give strategic insight on how firms can compete effectively, which the resource perspective can provide through building resources that are valuable, rare, and inimitable. However, acquiring resources only in a dynamic market environment is not enough for superior market performance (Hunt \& Madhavaram, 2019; Chi \& Tsai, 2012; Day, 2011; 2014). The RBV is static and takes an inside out perspective (Teece, 2014). Instead, a capability approach is required in dynamic environments.

\section{Capabilities approach}

The capabilities approach sought to deal with dynamic environments that the static RBV could not address. The capabilities approach extends the RBV by emphasising outside-in adaptive (Day, 2011) and dynamic capabilities (Teece, et al., 1997; Teece, 2014; 2016) for creation of market positions that are difficult to imitate. The capabilities approach traces sources of "defensible competitive advantages in the 
distinctive, hard-to-duplicate resources the firm has developed" (Itami, 1987; Rumelt, Schendel, and Teece, 1991 cited by Day, 1994:38). Firms must regularly emphasise on renewing themselves in the marketplace (Hunt \& Madhavaram, 2019). A capability refers to the ability to use resources to perform tasks, and come from the shrewd bundling of resources (Teece, 2014; Lin \& Wu, 2014). Capabilities bring tangible and intangible resources together as such form the glue of the organisation and are a special class of intangible resources that every organisation require in order to perform par excellence. Day (1994) considered "marketing capability as the capability of an enterprise to utilize its knowledge, technology, and resources to satisfy the needs of the market". As such, capabilities enable the movement from one advantage to another (Day 2014) through configuration of resources into dynamic capabilities (Bitencourt, et al., 2019; Teece, 2014; Chi \& Tsai, 2012) and adaptive capabilities.

Dynamic capabilities refer to "capabilities of a firm to integrate, learn and reconfigure internal and external resources" (Lin \& Wu, 2014: 408). Dynamic capabilities goes beyond knowledge and technological elements to include managerial and organisational capabilities (Teece, 2014). However, being dynamic is not sufficient to cope with contemporary market realities (Day 2011). According to Day (2011), "the inside-out stance of the dynamic capabilities approach inevitably limits the ability of the firm to anticipate rapid market shifts and become more resilient in the face of increasing volatility and complexity." Dynamic capability takes an inside-out approach (Day, 2014, 2011) as it begins with the firm and looks outside. The "ability of firms to understand and quickly adjust to their fast-changing markets ultimately depends on their adaptive capabilities" (Day, 2014). Adaptive capabilities emphasise exploration emerging from outside whilst dynamic exploration emerge from inside. However, both dynamic and adaptive capabilities complement each other. An organisation needs a balance as both enable development of competitive advantages in dynamic markets taking both inside-out and outside-in perspectives. Both adaptive and dynamic capabilities converge with resource-advantage (R-A) in the emphasis on continual renewal for superior performance (Hunt \& Madhavaram, 2019) as such are useful in predicting firm performance in digital marketing environments.

\section{McCarthy marketing mix model}

A marketing mix "involves everything that the firm can do to engage consumers and deliver customer value" (Kotler \& Armstrong, 2018). The 4Ps (product, price, place, promotion) is a classification of marketing activities (Kotler \& Keller, 2016). The marketing mix provides marketing elements that if properly managed can lead to profitability. Several researchers developed various models of the marketing mix concept. For example, Gronoos (1997) relationship marketing, Gordon (2012) social marketing mix, Ohmae (1982) three Cs, Robins (1991) and Lautenborn (1990) 4Cs, Constanidides (2002) 4S web marketing mix, Bennett, (1997) 5Vs, Kotler \& Keller, (2016) revised 4ps model. However, only McCarthy 4Ps model had been widely tested and accepted thus influential in marketing. The widely tested and accepted marketing concept (4Ps marketing mix) (Constantinides, 2002) help understand activities that a firm can engage in to create value (Kotler \& Armstrong, 2018; Chaffey, 2015: 363). Thus, the marketing mix remain valuable despite criticism for being static (Vorhies and Morgan 2005) and functional bias (Day, 2011). It still satisfies what Day and Moorman (2010) termed strategic marketing perspective that broadens the domain to encompass customer value creating capabilities. The marketing mix give a good foundation to understand and implement complex and interconnected marketing activities (Kotler \& Armstrong, 2018, Chaffey, 2015:363; Waterschoot \& Bulte, 1992) thus is significant in problem solving and decision making in marketing (Borden, 1984). The 4Ps are still useful for implementing marketing strategy (Chaffey, 2015:363) in the digital age (Ryan \& Jones, 2009). Kingsnorth, (2016) pointed out key questions that marketers can make from a digital perspective such as "whether your product can/will sell online", what channels are available for your product? "Are there opportunities to make it flexible to be more appropriate for online or mobile audiences"? These questions help develop appropriate digital marketing programs that fit the organisation's product goals and objectives.

Small firms are significantly different from large firms as small firms employ different strategies and marketing mixes (Borden, 1984) therefore, it is crucial to understand the marketing mix concept. While small firms tend to adopt push strategies of personal selling, large firms go for pull strategies because of the huge resources to involve consumers in product development and testing (Borden, 1984). 
Resources have a huge impact to marketing mix activities employed by a firm (Borden, 1984; Barney, 1991; Hitt, et al., 2017). It is therefore relevant to apply the marketing mix in assessing digital marketing activities or programs in small firms. As demonstrated by Chaffey, (2015) the 4Ps model can be truly relevant in designing and implementing digital marketing activities. Actually, the digital world brings more Ps to the same place (WSI, 2015). For example, social media enhance product experience (product) through conversations; create awareness of the product (promotion), make the product available (place), and provides prices (pricing).

\section{Conceptual framework}

Clark (2007) provides a framework for measuring market performance that included market assets, marketing activities and market performance outcomes. According to Clark (2007) market performance framework, marketing assets influence marketing activities, and activities influence intermediate outcomes whilst intermediate outcomes influence final outcomes. Therefore, Clark (2007) model formulates the basis for this study as shown in figure 1.

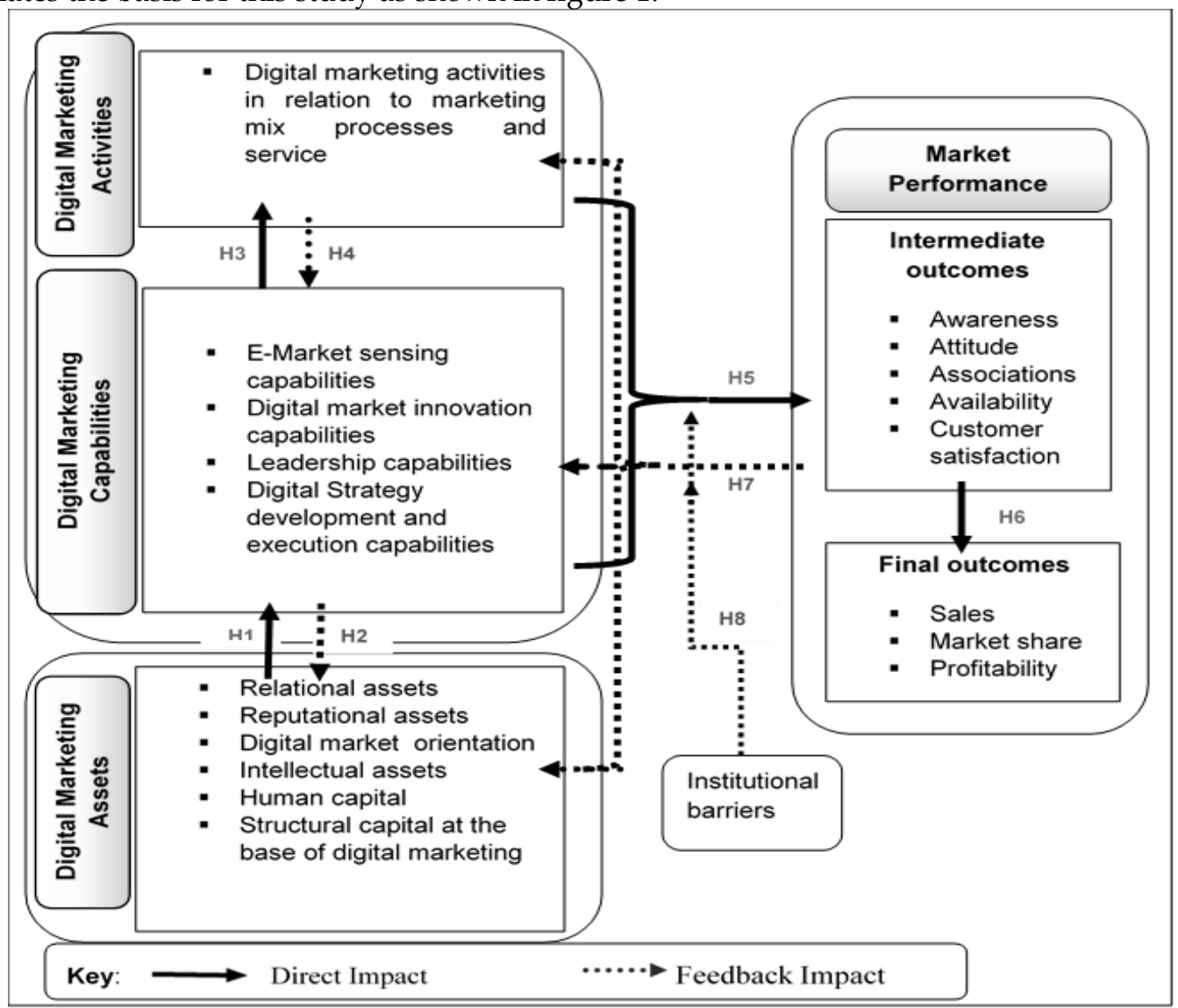

Figure 1: Conceptual framework

Source: Adapted from Clark (2007)

The model comprises four (4) sections 1) digital marketing assets, 2) digital marketing capabilities 3) digital marketing activities and 4) market performance. This model contributes to Clark (2007) framework in three ways. First, the proposed model takes a digital marketing resource and capability perspective. Second, the model includes capabilities (digital marketing capabilities), and finally the model incorporates institutional barriers as a moderating variable to market performance outcomes. In addition, the proposed model builds on existing knowledge that resources or assets are the foundation to build capabilities, in other words, capabilities are required to make use of resources, and capabilities influence all other activities and performance (Morgan, 2012; Day, 2011; Teece, et al., 1997). 


\section{Digital marketing assets.}

Digital marketing assets influence digital marketing capabilities (Day, 2011). As such the study conceptualises digital marketing assets as a foundation for digital marketing capabilities and activities. These resources are important because no research tested them on agro-processors especially from the Zimbabwean context.

Digital marketing assets consists structural capital or physical resources at the base of digital marketing that is infrastructure that add value to other processes, activities or resources (Edvinsson \& Sullivan, 1996; Morgan, 2012). It is significant to marketing and provides direct support to human resources through tangibles such as computers, telephones, servers, the internet, and intangibles such as expertise, processes, software, and systems. Structural capital includes intangible structural capital such as firm's culture and intellectual assets. However, this paper limit structural capital to assets such as computers, information systems, servers, telephone lines and customer databases as a foundation for digital marketing activities. Intellectual assets and culture (digital market orientation) stand-alone.

Human capital is the second digital marketing asset in this paper. Human capital comprises the managers and employees that develop and implement strategies (Moorman \& Day, 2016). It is concerned about people, their skills, creativity, and knowledge available as inputs into marketing capabilities of the firm (Morgan, 2012: Edvinsson \& Sullivan, 1996). Lack of adequate human capital negatively affect strategy implementation regardless of how great the idea could be (Hooley, et al., 2005). Exceptional human capital is time consuming, depend on hidden knowledge and skills, and may not be transferrable to other environmental settings. Therefore, it is important to test the extend to which agro-processors have people with digital marketing skills and knowledge as existing literature show that marketing skills cannot be easily transferred form one market to the other, yet they are crucial for superior market performance.

The third asset is intellectual assets. Intellectual assets are an accumulation of processed information (knowledge) used by the firm for value creation (Chen, 2005). It is the form of knowledge about the competitive environment such as market situation, competitors, customers, suppliers and other stakeholders (Srivastava, Fahey, \& Christensen, 2001). These intellectual assets positively influence market value and performance (Chen, 2005). Exclusive knowledge such as processes, data and software where proprietorship can be proclaimed (Edvinsson \& Sullivan, 1996) are considered valuable intellectual assets in this study. As such we conceptualise intellectual assets as digital marketing resources that require digital marketing capabilities to convert into profitable market activities and outcomes. Although research show that agro-processors rely on informal linkages and cultural connections, it is not known to what extend do these linkages provide valuable intellectual assets in the digital environment.

The fourth asset is digital market orientation. Market orientation is an extremely entrenched cultural aspect that gives firms a distinctive resource (Hooley, Cadogan \& Fahy, 2005), directs thinking and actions throughout the firm, as such develop values, norms and behaviours aligned to the market (Moorman \& Day, 2016; Narver \& Slater, 1990:21). Market orientation cuts across all functions of the organisation and market-oriented organisations focus all activities to creating outstanding customer service and value (Hooley, et al., 2005). However, traditional market orientation is inappropriate in the digital environment, as it does not fully address characteristics of digital environment (Habibi, Hamilton, Valos, John \& Brendan, 2015). Nevertheless, this study adopts widely tested and accepted traditional market orientation components of customer orientation, competitor orientation, and inter-functional coordination as Habibi, et al., (2015) e-market orientation constructs are similar to existing constructs. Therefore, digital market orientation is a deeply entrenched cultural orientation that calls organisations to focus on creating superior customer value through customer and competitor focus as well as an organisational-wide coordination in the digital environment. Frosen, Luoma, Jaakkola, Tikkanen \& Aspara, (2016) found that market orientation is a requirement for every business but does not lead to superior market performance, as such this study consider digital market orientation as an asset required for deployment of other digital marketing capabilities if full potential is to be realised.

Fifth are reputational assets. These represent key brands and market credibility that stimulate customer satisfaction, loyalty, market share and sales volume (Milfelner, Gabrijan \& Snoj, 2008; Hooley, et al., 2005) therefore a vital market asset. In addition, Hooley et al (2005) noted that well-known brands and 
companies have potential to ensue more sales and market share without necessarily creating satisfied and loyal customers. Reputational assets make it easy to attract best skills, customers and engage with other stakeholders. Although, small firms inherently lack properly branded products, this study intends to establish branding capabilities of agro-processors, and market credibility thereof. The study considers existence of branded products, ability to meet customer needs, corporate image, and market credibility as the reputational assets of the firm. Although extant literature (Zindiye, et al., 2012; FinScope, 2012; Mhazo, et al., 2012) has evidence that SMEs agro-processors lack reputable brands, the extend to which this weakness influence digital market performance is not known. Can weak brands in the physical marketplace translate to a weak brand electronically or can customers easily link the two? This paper intends to contribute to this discussion by assessing impact of reputational assets to digital market performance.

Sixth are relational assets or customer linking capabilities (Day, 1994). These are a firm's proficiency in identifying profitable relationships, developing, and nurturing relationships for a profit (Morgan, et al., 2009; Hooley, et al., 2005). Relational assets promote open marketing (Day, 2011) through linkages to networks outside the organisation. Outside networks are a critical resource that provide access to other links, business opportunities, market intelligence, collaborative product development, and solid communication networks. Product marketing consists of conversations happening in networks around the organisation (Hanna, Rohm \& Crittendenet, 2011) as such relationships profit both suppliers and customers (Morgan, Vorhies \& Masonet, 2009b). However, marketers must be able to select and develop only profitable relationships (Morgan, et al., 2009). This study considers relational assets to be critical for survival of small firms as relationships help develop new markets, give access to raw materials, finance, new knowledge and skills. This resource is important in this study, as small firms are widely known for their high informal linkages and connectivity. However, to what extent do linkages in the physical environment translate to profitable relational assets in the digital marketspace?

\section{Digital marketing capabilities}

Figure 1 conceptualise that capabilities enable digital marketing activities. The digital strategy development and execution capability relates to a firm's ability to create and implement strategy for attainment of organisational marketing objectives (Chaffey, 2015; Vorhies \& Morgan, 2005) in the process enhancing its resources and market position. A firm always need to clearly define its current position, where it wants to be, how to be there, specifying exact details of getting there, tactics, and performance monitoring metrics. Chaffey (2015) emphasised the need for control to be able to modify strategies. Digital analytics enhance this monitoring through real time tracking of users on platforms such as social media, mobile and desktop applications. Vorhies \& Morgan, (2005) found strategy development and implementation capabilities to influence market performance. Failure to define clearly strategy can lead to missed opportunities, wrong direction, narrow integration, inadequate collection of customer data, and resource wastages (Chaffey, 2015). Small firms generally lack planning (Gilmore, et al., 2007) as such this study seeks to assess extend to which planning is prevalent in the digital marketing environment. The study views strategy development and execution capability as a unique resource that has potential to differentiate a firm from its competitors. The way strategies are developed, integrated, and executed can provide causal ambiguities, interdependence, and connectedness that competitors cannot easily imitate.

Second e-market sensing capabilities - involve active gathering, interpretation, and dissemination of market information (Day, 1994). The digital marketing environment require that firms monitor constantly changes and anticipate customer reactions so that there is proactive action. Digital technologies allow organisations to easily sense and respond to market needs (Setia, Venkantesh \& Joglekar, 2013). E-market sensing is crucial for organisational learning and this builds an organisation's knowledge base contributing to competitive value creation. E-market sensing capabilities make market orientation a reality through new knowledge that generate new marketing capabilities which in turn are used to gather market insights and respond to customer needs (Day, 2011, 2014). Exceptional market sensing provides opportunities to lower cost through better deployment of resources, pricing decisions (Morgan, et al., 2009), better forecasting, and customer service. Properly executed, this can lead to profit growth from markets previously underserved; therefore, e-market sensing is predominantly important as a harmonising capability (Day, 1994, 2014). However, to what extent do agro-processors sense their 
markets? There is no evidence to the usage of technology for e-market sensing by agro-processors in Harare thereby necessitating this study. This study considers e-market sensing capability as an important, inimitable and hard to develop resource that activates and influence digital marketing activities and market performance.

Third are digital market innovation capabilities. Innovation capability are the skills and knowledge required to successfully recognise, grasp, and enhance prevailing technologies, and develop new ones (Romijn \& Albaladejo, 2002). Barrett, Davidson, Prabhu \& Vargo, (2015:45) deriving from Yoo et al. (2010, 726) defined digital innovation as the novel blending of digital and physical components to create products that eliminate industry boundaries. Digital market innovation has potential to contribute to development of sustainable competitive advantage (Hooley, et al., 2005) and drive development regardless of infrastructure and other resource limitations (Barrett, et al., 2015). However, to what extent do agro-processors innovate and use this innovation to create sustainable competitive advantage? Innovation in developing countries is different to that of developed markets due to resource differences (Barrett, et al., 2015) as such innovations in resource-constrained markets generally involve adjustments to delivery or business model unlike technology itself. It remains unknown though how agro-processors in Harare innovate? What kind of resources do they need? In addition, under what conditions do they innovate? Although research has evidence that ongoing knowledge acquisition, comprehensive customer understanding (Trainor, Krush \& Agnihotriet, 2013), customer needs (Barrett, et al., 2015) and human resources (Aryanto, Fontana \& Afiff, 2015) lead to market innovation there is no evidence that the same resources influence innovation in agro-processors. In view of innovation capability contributions to resource-constrained environments, it is important to establish contribution of such capabilities in digital marketing environments. This study considers digital market innovation capabilities as abilities to create value through development of new digital market ideas, processes, models and products utilising digital market data and technologies. This perspective contributes to innovation capabilities knowledge in developing markets.

Leadership capability is the fourth digital marketing capability in the model. This is the ability to lead, manage, motivate, and coordinate activities within an organisation. Possession of exceptional human capital is not enough, there is need to bring that capital together to create value in the organisation. Managerial and organisational processes in an organisation influence its competitive advantage (Teece, et al., 1997; Teece, 2014). Management of human resources and their development influence motivation and loyalty, which in turn affects strategy implementation. Unlike other studies, this study deliberately chose leadership instead of managerial capability because most SMEs do not have clear organisational structures that clearly define management roles. Instead, a bundle of skills is generally available, and the owner usually makes all the strategic decisions. As such, it is crucial to refer to capabilities to lead and direct all other activities. However, there is no evidence on leadership capabilities of these SMEs agroprocessors especially when it concerns digital marketing activities. To what extend are the managers able to give direction, motivate and coordinate digital marketing activities? As such, this study considers leadership capabilities as an important resource that needs interrogation.

\section{Digital marketing activities}

Existing research (Clark, 2007 and Morgan et al, 2012) classify capabilities concerning marketing mix elements differently. Whilst Clark (2007) considers marketing mix capabilities to be marketing activities which are a result of an organisation's assets, Morgan et al (2012) consider marketing mix elements to be merely a capability that an organisation can possess. In view of the different classifications, capabilities concerning marketing mix processes can be either a resource (capability) or an activity. Marketing mix consists activities at the front-end of organisations that interact with customers (Day , 2011). Capabilities and activities intricately connect because capabilities enable execution of activities (Day, 1994). Teleghani, Akhlagh \& Sani, (2013) suggested digital marketing activities must be centred on internet applications for customer service, activities related to sales, distribution, e-research and management related functions.

This paper considers capabilities in relation to marketing mix elements as an activity and intends to interrogate relationship between digital marketing resources (assets), capabilities, and digital marketing activities contextualised in the 4Ps model. If for example an organisation has high digital market 
innovation capabilities, what would be the influence of these capabilities to marketing mix elements? Product development requires understanding of customer needs and wants that market sensing brings. Digital market interactions on websites and other e-channels improve new product development through enhanced engagements, customer relationships, demand, and distribution management (Trainor, et al., 2013). Unique value can be in use of strategic distribution channels that competitors find difficult to match thereby becoming a customer value leader. Therefore, the study posits that superior execution of activities requires deep market insights brought by market sensing, leadership, digital market innovation, strategy development and execution capabilities.

\section{Market performance}

Existing literature (Morgan, 2012; Day, 2011; Morgan, et al., 2009b) has evidence that marketing resources influence firm performance. Marketing resources (Hooley, et al., 2005 and marketing activities (Clark, 2007) influence market performance therefore a priority for marketers to link marketing capabilities and actions to performance (Morgan, et al., 2009). Whilst most studies focussed on Western markets and traditional marketing resources this study, takes a developing country and digital marketing perspective, and splits market performance into intermediate and final outcomes. This is important to establish extend to which digital marketing activities influence both intermediate and final outcomes.

\section{Intermediate outcomes}

Organisations develop, communicate, and make available product information before customers can make purchase decisions. Customers have to be convinced of value offered relative to competitor offerings before they buy. Customers thus have to be aware before taking any action. After awareness, marketers can measure consumer knowledge and feeling, emotions and associations in memory. This knowledge and emotions translate to attitudes (Clark, 2007) which affect customer decisions. Website design and electronic marketing aspects are important forecasters of delivery, brand image, and quality (Tsiotsou \& Vlachopoulou, 2011) thus crucial in formulating customer immediate outcomes. However, extend to which these elements affect immediate outcomes in SMEs agro-processors who are informally connected, and rely on personal networks is not known. Therefore, this study intends to measure awareness levels, brand associations, availability through different channels, and overall customer satisfaction before realisation of sales, market share, and profitability on agro-processors in Harare.

\section{Final outcomes}

Organisational performances concerns cost based measures (profit measures) and revenue based (sales and market share) (Kirca, Jayachandran \& Bearden, 2005). Whilst marketers focus on increasing sales, there is need always to make sales profitably (Clark, 2007) thus, growing recognition of profitability in market performance measurement. Most managers and investors view profit growth as essential although they rarely use it as a measure of marketing performance (Morgan, et al., 2009). However, profit growth is crucial as it increases a firm's stock value. This study measures sales, market share, and profitability as final outcomes. Unlike most studies, the study interrogates the relationship between intermediate outcomes and final-outcomes in the context of agro-processors. This is important as it contributes to knowledge on extend to which intermediate outcomes influence final-outcomes in the market performance of agro-processors.

\section{Institutional barriers}

Interfering in the interaction of digital marketing activities and outcomes are institutional barriers. These are deterrents to business operations (Mair, Marti \& Ventrescaet, 2006) and can be formal, informal, or environmental (Aidis, 2005). Formal barriers include government systems, laws, and other business legislations whilst informal include corruption, late payments from clients, and frequent tax inspections. Environmental barriers comprise low purchasing power, lack of investment funds and competition from illegal businesses. It is important to note that formal institutions are weak in subsistence markets consequently much reliance is on informal institutions (Rivera-Santos, Ruffin \& Kolk, 2012) that may not promote establishment of competitive enterprises. Firms in developing countries face more government interferences, corruption, and environmental challenges than those in developed markets (Aidis 2005). However, to what extent do institutional barriers (such as corruption and environmental challenges) 
negatively affect competitiveness of agro-processors Harare, Zimbabwe? In addition, are informal institutions valid in promoting competitiveness of SME agro-processors in the digital marketing environment? The study therefore posits that institutional barriers negatively affect digital market performance of agro-processors in Zimbabwe.

\section{Discussions and conclusions}

This paper produced a conceptual framework interrogating digital marketing resources, capabilities, and market performance. The researchers argue that possession of certain digital marketing resources and capabilities has an impact on market performance of agro-processors. The study made several propositions connected to this argument, first, learning from Bitencourt, et al., (2019); Day, (2011), (2014); Teece, (2014) and Teece, et al., (1997) being that, digital marketing assets influence digital marketing capabilities and secondly, influenced by Clark (2007) idea of feedback effects, digital marketing capabilities influence digital marketing assets through feedback effects. Third, digital marketing capabilities positively affect digital marketing activities. Digital marketing activities are therefore a product of resources and capabilities possessed by a firm. If resource endowment is low, the expectation is that digital marketing activities will be low or limited. In this study, digital marketing activities are endeavours related to marketing mix elements and service such as online promotions, digital channels and electronic communications (Chaffey \& Smith, 2017; Chaffey, 2015). The fourth proposition is that digital marketing activities indirectly influence digital marketing capabilities whilst activities positively influence intermediate outcomes. Intermediate outcomes influence final-outcomes whilst final-outcomes have a feedback effect on digital marketing resources and capabilities (Clark, 2007). Finally, guided by the work of (Aidis, 2005; Rivera-Santos, et al., 2012) institutional barriers negatively influence digital marketing performance. This study considered two types of outcomes, intermediate and final outcomes. Intermediate happen before final outcomes. For example, there is need for awareness (intermediate outcome) before a sale (final outcome) can take place.

While the RBV and capabilities approach provide a strong foundation to understand impact of resources on firm performance, they do not clearly explain resources required for optimal performance in a digital environment. In addition, there is need to establish extend to which researchers can apply tenets of the RBV to digital marketing environments. For example, to what extend can a resource be rare and inimitable in the digital environment? Existing research that applied the RBV concept focussed more on traditional marketplace environment. From a Zimbabwean context, leading researchers on agroprocessors such as (Mhazo, et al., 2012; Zindiye, et al., 2012) do not focus on digital marketing resources, capabilities and performance. Therefore, this study contributes to knowledge on marketing in developing countries by interrogating relationships between digital marketing resources, capabilities and market performance. The study contributes to digital marketing literature by applying existing knowledge to a digital and developing country context. This is crucial to the Zimbabwean context because existing research (Matsongoni \& Mutambara, 2018; Mapakame, 2017; Bomani, 2016; FinScope, 2012; Mhazo, et al., 2012; Zindiye, et al., 2012) mainly focus on SME financial issues, accounting practices, government policy, general challenges and constraints.

Existing literature does not fully address developing countries issues and knowledge is difficult to transfer from one market to the other (Sheth, 2011). Transferability is limited as marketing is contextual. The model proposed helps researchers understand extent to which both existing traditional and digital marketing knowledge and concepts apply to digital marketing in developing markets. In addition, the developed model contributes to the digital marketing performance measurement debate by defining digital marketing specific resources, and capabilities. To that end, there is need to test the proposed framework so that more knowledge and contributions are developed. Additionally, debate on what constitutes a marketing resource continue, with no agreement on classifications yet resource classification and selection is important ( $\mathrm{Lin} \& \mathrm{Wu}, 2014)$. This study intends to contribute by developing a model of resources, capabilities and market performance that researchers must empirically test in a digital marketing environment. Expected results brings new knowledge to the RBV and capability approach by defining new class of resources and capabilities applicable to the digital marketing environment in a developing market context. This type of knowledge is important because researchers such as Wymbs, (2011) and (Day, 2011) noted that emerging technological environment is challenging existing marketing 
practices and marketing in developing markets is not the same as in developed countries therefore marketing practices and theories cannot be easily transferred (Sheth, 2011).

The marketing mix model (4Ps model) is silent on the resources and capabilities required to execute the various marketing mix activities or programs. To this end, this study contributes by developing a new set of resources that marketers and researchers can apply in the Zimbabwean context.

The proposed conceptual model implies that organisations need to develop strong digital marketing assets foundation before they can deploy any capabilities at the same time developing capabilities to execute profitable digital marketing activities. Secondly, organisations must target developing positive intermediate outcomes as they influence final outcomes. In addition, institutional barriers negatively affect performance therefore, organisations must consistently lobby for a formalised environment or develop associations that help create favourable environment (Rivera-Santos, et al., 2012; Mair, et al., 2012). To researchers, the study implies vigorous testing of the model in different developing markets contexts, and in different industries to come up with widely acceptable framework and contributions.

\section{Limitations and direction for future research}

The major limitation for this study is that the identified constructs are conceptual, and researchers must test the framework. More so, some constructs are from previous marketing research that was not digital marketing oriented which may limit applicability in the digital marketing context. The researchers heavily relied on literature from emerging and developed markets in development of the constructs. This may pose challenges to application of the constructs in a developing market context since marketing is contextual. This study deliberately picked resources and capabilities the researchers considered important in their context as the list is not exhaustive (Day, 1994). Selective picking of constructs could leave out some important ones thereby not giving a true picture of the importance of digital marketing resources and capabilities to market performance.

Further research is required to test empirically the conceptual model. Researchers must test the model in different marketing contexts to develop generally acceptable results. Researchers must further explore and develop concepts testable and measurable using objective digital tools.

\section{References}

Aidis, R., (2005). Institutional Barriers to Small- and Medium-Sized Enterprise Operations in TransitionCountries. Small Business Economics, 25(4), pp. 305-318.

Aryanto, R., Fontana, A. \& Afiff, A. Z., (2015). Strategic human resource management, innovation capability and performance.An emperical study in Indonesia software industry.. Procedia - Social and Behavioural Sciences., Volume 211, pp. 874-879.

Barney, J., (1991). Firm resources and sustained competitive advantage. Journal of Management, 17(1), pp. 99-120.

Barney, J. B. \& Hesterly, W. S., (2015). Strategic Management and Competitive Advantage. Concepts and Cases.. 5th ed. Edingburgh Gate Harlow: Pearson.

Barrett, M., Davidson, E., Prabhu, J. \& Vargo, S. L., (2015). Service innovation in the digital age: Key contributions and future directions.. MIS Quarterly, 39(1), pp. 135-154.

Bitencourt, C. C. et al., 2019. The extended dynamic capabilities model; a meta-analysis.. European Management Journal.

Bomani, M., (2016). Government policies and strategies in dealing with challenges confronting small and medium enterprises: $a$ case of Harare, Zimbabwe., Pietermaritzburg: University of Kwazulu-Natal [Unpublished Phd thesis].

Borden, N. H., (1984). The concept of the marketing mix.. Journal of Advertising Research., Volume 3, pp. 7-12.

Chaffey, D., (2015). Digital business and e-commerce management: Strategy, Implementation and Practice.. 6th ed. Edinburgh Gate: Pearson Education Limited.

Chaffey, D. \& Smith, P., (2017). Digital Marketing Excellence: Planning, Optimizing and Integrating Online Marketing. 5th ed. New York: Routeledge.

Chen, M.-C., (2005). An empirical investigation of the relationship between intellectual capital and firms' market value and financial performance. Journal of Intellectual Capital , 6(2), pp. 159-176.

Chi, S.-Y. \& Tsai, C.-H., (2012). Dynamic capability, knowledge, learning, and firm performance.. Journal of Organizational Change Management., 25(3), pp. 434-444.

Clark, B., (2007). Measuring marketing performance: research, practice and challenges. In: A. Neely, ed. Business Performance Measurement. Cambridge: Cambridge University Press, pp. 36-63.

Constantinides, E., (2002). The 4S Web-Marketing Mix Model.. Electronic Commerce Research and Applications., Volume 1, pp. 57-76. 
Day, G. S., (1994). The Capabilities of Market-Driven Organizations. Journal of Marketing, 58(4), pp. 37-52.

Day, G. S., (2011). Closing the Marketing Capabilities Gap.. Journal of Marketing, Volume 17, pp. 183-195.

Day, G. S., (2014). An outside-in approach to resource-based theories.. Journal of the Academy of Marketing Science., Volume 42, pp. 27-28.

Edvinsson, L. \& Sullivan, P., (1996). Developing a Model for Managing Intellectual Capital.. European Management Journal, 14(4), pp. 356-364.

FAO, (1999). The agroprossessing industry and economic development. [Online] Available at: http://www.fao.org/docrep/w5800e/w5800e12.htm [Accessed 28 September 2016].

FinScope, (2012). FinScope MSME Survey Zimbabwe 2012, Midrand, South Africa: Finmark.org.

Frosen, J. et al., (2016). What Counts Versus What Can Be Counted: The Complex Interplay of Market Orientation and Marketing Performance Measurement. Journal of Marketing, Volume 80, pp. 60-78.

Gilmore, A., Gallagher, D. \& Henry, S., (2007). E-marketing and SMEs: Operational lessons for the future. European Business Review, 19(3), pp. 234-247.

Gordon, R., (2012). Re-thinking and re-tooling the social marketing mix.. Australasian Marketing Journal., Volume 20, pp. 122-126.

Habibi, H. et al., (2015). E-marketing orientation and social media implementation in B2B marketing. European Business Review, 27(6), pp. 1-18.

Hanna, R., Rohm, A. \& Crittenden, V. L., (2011). We are all connected. The power of the social media ecosystem.. Business Horizons.

Hitt, M. A., Ireland, D. R. \& Hoskisson, R. E., (2017). Strategic Management. Competitiveness and Globalisation. Concepts and Cases.. 12 edition ed. Boston: Cengage Learning.

Hooley, G., Cadogan, G. \& Fahy, J., (2005). The performance impact of marketing resources. Journal of Business Research, Volume 58, pp. 18-27.

Hunt, S. D. \& Madhavaram, S., (2019). Adaptive marketing capabilities, dynamic capabilities, and renewal competences: The "outside vs. inside" and "static vs. dynamic" controversies in strategy.. Industrial Marketing Management.

Kingsnorth, S., (2016). Digital marketing strategy: An integrated approach to online marketing.. 1st ed. London: Kogan Page.

Kirca, A. H., Jayachandran, S. \& Bearden, W. O., (2005). Market Orientation:A Meta-Analytic Review and Assessment of Its Antecedents and Impact on Performanc. Journal of Marketing, Volume 69, pp. 24-41.

Kotler, P. \& Armstrong, G., (2018). Principles of marketing. 17th edition ed. Harlow: Pearson.

Kotler, P., Kartajaya, H. \& Setiawan,I., (2017). Marketing 4.0: Moving from traditional to digital.. New Jersey: Wiley \& Sons.

Kotler, P. \& Keller, K. L., (2016). Marketing management: global edition. 15 ed. Essex: Pearson.

Lin, Y. \& Wu, L.-Y., (2014). Exploring the role of dynamic capabilities in firm performance under the resource based view framework.. Journal of Business Research., pp. 407-413.

Mair, J., I, M. \& Ventresca, M., (2012). Building inclusive markets in rural Bangladesh: how intermediaries work institutional voids. Academy of Management Journal, 65(4), pp. 819-850.

Mapakame, E., (2017). Zimbabwe: Manufacturing sector poised for further growth.. [Online] Available at: https:/ / allafrica.com/stories/201707240580.html [Accessed 12 September 2018].

Matsongoni, H. \& Mutambara, E., (2018). An assessment of informal SMEs' potential in an African economy theoretical and conceptual framework.. Public and Municipal Finance, 7(2), pp. 6-17.

Mhazo, N., Mvumi, B. M., Nyakudya, E. \& Nazare, R. M., (2012). The status of the agro-processing industry in Zimbabwe with particular reference to small- and medium-scale enterprises.. African Journal of Agricultural Research, 7(11), pp. 1607-1622.

Milfelner, B., Gabrijan, V. \& Snoj, B., (2008). Can Marketing Resources Contribute to Company Performance?. Organizacija, 41(1), pp. 3-13.

Moorman, C. \& Day, G. S., (2016). Organising for marketing excellence. American Marketing Association, Volume 80, pp. 6-35.

Morgan, N. A., (2012). Marketing and Business Performance. Academy of Marketing Science, Volume 40, pp. 102-119.

Morgan, N. A., Clark, B. H. \& Gooner, R., (2002). Marketing productivity, marketing audits, and systems for marketing. Journal of Business Research, Volume 55, pp. 363-375.

Morgan, N. A., Slotegraaf, R. A. \& Vorhies, D. W., (2009). Linking marketing capabilites with profit.. International Journal of Research in Marketing, Volume 26, pp. 284-293.

Morgan, N. A., Vorhies, D. W. \& Mason, C. H., (2009b). Market Orientation, Marketing Capabilities and Firm Performance. Strategic Management Journal, Volume 30, pp. 909-920.

Narver, J. C. \& Slater, S. F., (1990). The effects of market orientation on business profitability. Journal of Marketing, Volume 54, pp. 20-35. 
Parsons, A., Zeisser, M. \& Waitman, R., (1998). Organising today for the digital marketing of tomorrow. Journal of Interactive Marketing, 12(1), pp. 31-46.

Porter, M. E., (1979). The structure within industries and companies performance.. The Review of Economics and Statistics., 61(2), pp. 214-227.

Porter, M. E., (2008). The five competitive forces that shape strategy.. Havard Business Review, pp. 23-41.

POTRAZ, (2017). Abridged annual postal and telecommunications sector performance report 2017., Harare: Postal and Telecommunications Regulatory Authority of Zimbabwe (POTRAZ).

Rambe, P., (2018). The influence of internationalisation of labour on the performance of small scale rural based agricultural firms: A South African perspective.. Acta Commecii- Independent Research Journal in the Management Sciences., Volume 1, pp. 1-14.

Reeg, C., (2015). Micro and Small Enterprises as Drivers for Job Creation and Decent Work, s.l.: German Development Institute.

Rivera-Santos, M., Ruffin, C. \& Kolk, A., (2012). Bridging the institutional divide: Partnerships in subsistence markets. Journal of Business Research, Volume 65, pp. 1721-1727.

Romijn, H. \& Albaladejo, M., (2002). Determinants of innovation capability in small electronics and software firms in southeast England.. Research Policy, Volume 31, pp. 1053-1067.

Setia, P., Venkantesh, V. \& Joglekar, S., (2013). Leveraging digital technologies: How information quality quality leads to localised capabilities and customer service performance.. MIS Quarterly, 37(2), pp. 565-590.

Sheth, J. N., (2011). Impact of emerging markets on marketing: Rethinking existing perspectives and marketing. Journal of Marketing, Volume 75, pp. 166-182.

Srivastava, R. K., Fahey, L. \& Christensen, K. H., (2001). The Resource-Based View and Marketing: The Role of Market-Based Assets in Gaining Competitive Advantage. Journal of Management, 27(6), pp. 777-802.

Srivastava, R. K., Shervani, T. A. \& Fahey, L., (1998). Market based assets and shareholder value: A framework for analysis. Journal of Marketing, Volume 62, pp. 2-18.

Stone, M. D. \& Woodcock, N. D., (2014). Interactive, direct and digital marketing A future that depends on better use of business intelligence. Journal of Research in Interactive Marketing, 8(1), pp. 4-17.

Teece, D. J., (2014). A dynamic capabilities-based entrepreneurial theory of the multinational enterprise.. Journal of International Business Studies., Volume 45, pp. 8-37.

Teece, D. J., (2016). Dynamic capabilities and enterpreneurial management in large organisations: Toward a theory of the (entrepreneurial) firm.. European Economic Review., Volume 86, pp. 202-216.

Teece, D. J., Pisano, G. \& Shuen, A., (1997). Dynamic capabilities and strategic management.. Strategic Management Journal., 18(7), pp. 509-533.

Teleghani, M., Akhlagh, E. M. \& Sani, A. A., (2013). Impact of Electronic Marketing on the Performance of PistachioExporting Companies in Iran. Journal of Basic and Applied Scientific Research, pp. 211-217.

Trainor, K. J., Krush, M. T. \& Agnihotri, R., (2013). Effects of relational proclivity and marketing intelligence on new product development.. Marketing Intelligence Planning, 31(7), pp. 788-806.

Tsiotsou, R. H. \& Vlachopoulou, M., (2011). Understanding the effects of market orientation and e-marketing on service performance. Marketing Intelligence E Planning, 29(2), pp. 141-155.

UN Zimbabwe, (2016). Eradicate extreme poverty and hunger. [Online] Available at:

http://www.zw.one.un.org/togetherwedeliver/millennium-development-goals/1-eradicate-extreme-poverty-and$\underline{\text { hunger }}$

[Accessed 4 September 2016].

Vorhies, D. W. \& Morgan, N. A., (2005). Benchmarking marketing capabilities for sustainable competitive advantage. Journal of Marketing, Volume 69, pp. 80-94.

Waterschoot, v. W. \& Bulte, v. d. C., (1992). The 4P of marketing mix classification revisited.. Journal of Marketing., 56(4), pp. 83-93.

WSI, (2015). Digital Minds. 12 things every business need to know about digital marketing. 2nd edition ed. Victoria: FriesenPress.

Wymbs, C., (2011). Digital marketing: The time for a new 'academic major' has arrived. Journal of Marketing Education, 33(1), pp. 93-106.

Zindiye, S., Chiliya, N. \& Masocha, R., (2012). The impact of government and other institutions' support on the performance of small and medium entreprises in the manufacturing sector in Harare, Zimbabwe.. International Journal of Business Economics Research, 3(6), pp. 655-657. 